NBER WORKING PAPER SERIES

\title{
AFFIRMATIVE ACTION AS EARNINGS REDISTRIBUTION: \\ THE TARGETING OF COMPLIANCE REVIEWS
}

Jonathan S. Leonard

Working Paper No. 1328

NATIONAL BUREAU OF ECONOMIC RESEARCH 1050 Massachusetts Avenue

Cambridge, MA 02138

April 1984

I thank Finis Welch, Jim Smith, and J. Griffin Crump for their comments. This research was supported in part by the Office of the Assistant Secretary for Policy of the U.S. Department of Labor, and by the School of Business, University of California at Berkeley. The research reported here is part of the NBER's research program in Labor Studies. Any opinions expressed are those of the author and not those of the National Bureau of Economic Research or the Department of Labor. 
NBER Working Paper \#1328

April 1984

\title{
Affirmative Action as Earnings Redistribution: \\ The Targeting of Compliance Reviews
}

\begin{abstract}
$\underline{\text { ABSTRACT }}$
Affirmative action may be broadly conceived of as pursuing either the goal of reducing discrimination or that of redistributing jobs and earnings. I attempt to infer the ends of affirmative action policy by analyzing the historical record of enforcement. Optimal enforcement strategies are developed for both the anti-discrimination and the earnings redistribution models, and then compared with new data on the actual targeting of affirmative action compliance reviews during the late 1970s. I find that establishments with very low proportions of minority or female workers are not significantly more likely to be reviewed, but that white-collar intensive establishments are more likely to be reviewed. This indicates the shortcomings of the anti-discrimination model in explaining the OFCCP's behavior, and suggests the potential usefulness of the earnings redistribution model.
\end{abstract}

Jonathan S. Leonard 350 Barrows Hall School of Business University of California Berkeley, California 94720 (415) 642-7048 


\section{Introduction.}

In the beginning, the purpose of the affirmative action obligation placed on federal contractors by a series of Exccutive Orders was to eliminate current discrimination in employment. Under Fxecutive Order 11246, federal contractors agree "not to discriminate against any employee or applicant for employment because of race, color, religion, sex or national origin, and to take affirmative action to ensure that applicants are employed and employees are treated during employment without regard to their race, color, religion, sex or national origin." [3 C.F.R. 169 $202(1)(1974)]$. This language imposes two obligations: first, not to discriminate: second, whether or not there is any evidence of discrimination, to take affirmative action not to discriminate. It is a measure of this nation's progress that the first obligation is now largely beyond debate. The redundant sounding second obligation, however, is anything but. It has provoked continual controversy, and its meaning and effect are not well understood. In the heated political arguments over whether and what affrmative action should be, mythic visions have come to overwhelm any clear conception of what affirmative action actually is.

Affirmative action can be broadly conceived of as pursuing either antidiscrimination or job and earnings redistribution goals. That is to say, it can either pursue equality of opportunity or equality of result. Given the historical record, progress toward the former goal will often entail progress toward the latter. Job or earnings redistribution, however, can proceed with little if any amelioration of discrimination. The central question this paper seeks to answer is: what are the actual goals of affirmative action? The approach taken here is to infer the ends of affirmative action policy from an analysis of the historical record of actual enforcement.

The analysis develops in five parts. Section II develops two polar models of how affrmative action should be enforced: first assuming that the goal of affrmative action is to reduce employment discrimination, and second assuming that the goal is to 
redistribute jobs and earnings to minorities and females. Section III briefly reviews the lonely past work on this question, and Section IV discusses the new and detailed data set developed to test the competing hypotheses. The main empirical findings are presented in Section V. Section VI presents the conclusion of this research: the targeting of affirmative action compliance reviews is inconsistent with a program whose primary purpose is to fight the most blatant form of current employment discrimination. The evidence to be presented here suggests that affirmative action can be more usefully thought of as a program to redistribute jobs and earnings to minorities and females.

\section{Models of Regulatory Behavior.}

Since 1978, the Office of Federal Contract Compliance Programs (OFCCP) has been responsible for enforcing affirmative action under Executive Order 11246. In particular, the OFCCP is the federal agency with primary responsibility for pursuing cases of systematic employment discrimination. If the OFCCP were concerned solely with reducing current employment discrimination, how should it then target enforcement pressure? How should it decide which establishments to review?

Although subtle forms of discrimination may not reveal themselves in the underrepresentation of members of a given group, statistical underrepresentation does provide prima facie evidence, though certainly not proof, of discrimination. Complete screening for discrimination would test every aspect of the employment relationship for color and sex blindness. This is costly, so it seems reasonable to select for further investigation those establishments in which minorities or females are underrepresented in employment. While the operational definition of underrepresentation has been debated in lengthy detail in the courts and elsewhere, all that needs to be pointed out here is that by issuing a set of vague and self-contradictory regulations. the OFCCP has left itself virtually unrestrained in this area. 
To simplify the discussion, assume a fixed and known labor supply, common to all firms. Let $\pi$ percent of a labor force population be black, with population variance $(\pi)(1-\pi)$. Think of a firm's employment practices as a color blind draw with replacement from this population. The expected value of $P$, the sample mean percent black, is $\pi$. The variance of the sample mean is then $(\pi)(1-\pi) / N$, where $N$ is firm size. If no firms discriminate, then randomly we expect $2.5 \%$ of all firms to employ fewer than $\pi-2 \pi(1-\pi) / N$ percent black.

The legal and administrative use of underrepresentation as prima facie evidence of discrimination presumes that discriminators are more likely to be in the tail of the distribution. But how should the OFCCP select the threshold al which it will reject the null hypothesis of non-diserimination? This will depend on the relative cost of making type I and type II errors.

One goal of the regulatory bureaucracy is to live and grow by maximizing net political support. If the OFCCP's political base lay in anti-discrimination it would gain political support by minimizing type II errors. If this were all that mattered it would set a low threshold and would pressure all firms. Balancing this incentive is the cust. of a type I error. At low thresholds, many non-discriminating firms will be harassed, breeding antagonism and eating away political support ${ }^{1}$.

The regulator's tradeoff involves solving:

$$
\underset{p}{M A X} G=[1-\beta(P)] Z-\alpha(P) C_{I}-\beta(P) C_{I I}-\lambda\left[N(P) C_{P}-X-Y\right]
$$

with first order condition:

$$
-\beta\left[Z+C_{I I}\right]-\alpha^{\prime} C_{l}
$$

where $P_{t}$ is the threshold level. Firms with percent black below $P_{t}$ are audited. $\alpha\left(P_{t}\right)$ is the probability of a type I error, of falsely accusing under the null hypothesis that firms do not discriminate. $\alpha^{\prime}>0$. $\beta\left(P_{t}\right)$ is the probability of a type II error, letting the guilty go. $\beta<0$. $N\left(P_{t}\right)$ is the densily function of number of fims by percent black. 
$\mathrm{Z}$ is the political benefit of correctly identifying a discriminating firm.

$C_{I}$ is the political cost of a type I error: falsely pursuing the innocent.

$C_{Z I}$ is the political enst of a type Il error: allowing discriminators to uperate unchallenged.

$C_{R}$ is the cost of a review.

$\mathrm{X}$ is any politically neutral but financially costly activity of the regulator. $\mathrm{Y}$ is the regulator's budget.

The first order condition states that to maximize political support while satisfying the budget constraint, the regulator should increase $P_{t}$ until the marginal benefit of catching discriminators is equal to the marginal cost of false accusations, additional reviews, and missing discriminators.

The variance of the sample mean decreases with sample size, so the prima facie evidence of discrimination in a firm with a given percent black is statistically stronger the larger the work force of the firm. Intuitively, as the firm draws a larger sample it is more likely to resemble the population. To hold the probability of a type I error fixed, as firm size $n$ increases, $P_{t}$ - the level below which regulatory pressure is applied - must also increase. We know that $\alpha=\operatorname{Prob}\left(P<\pi-k_{\alpha} \sigma\right)$, where $\pi$ is the population mean, and $k_{\alpha}$ is read off a table of the binomial or normal distribution. The threshold level $P_{t}$ is equal to $\pi-k_{\alpha} \sigma$, where $\sigma=(\pi(1-\pi) / n)^{1 / 2}$. So

$$
d P_{t} / d n=\left(k_{a} / 2 n\right)((\pi(1-\pi)) / n)^{1 / 2}
$$

This is positive, so holding $\alpha$ fixed implies that as the firm size inrreases the regulator should pursue firms with higher black representation. This is important since there is in fact a broad range of firm sizes, and a may be presumed to be snall. It would be irrelevant for large $\alpha$, since $k_{\alpha}$ goes to infinity as $\alpha$ increases.

Can other factors overturn the implication that regulators attempting to reduce discrimination in enployment as we have defined it above, should pursue firms in the 
lower tail of the distribution first? Spillover effects are an important consideration. Shouldn't the OFCCP go after the firms with the highest representation of minorities or females? This may set an example to all firms of the OFCCP's high standards, and send the message that none are free from sin. Alternatively, what if there is tipping behavior, or if some firms are pushovers that yield easily to pressure, so that the regulatory costs of achieving a given increase in minority or female representation are lower at a firm with a high initial representation'? The problem with both these scenarios is that they create perverse incentives over time. Punishing friends and ignoring enemies eventually undermines the legitimacy and effectiveness of the program.

The main testable implications of this model then are that the OFCCP should target for compliance reviews those firms in the bottorn tail of the distribution of minurity or female representation, and that it should proceed further up this tail toward the mean as firm size increases ${ }^{3}$.

\section{Targeting to Redistribute Farnings}

To think of affirmative action solely as policy against discrimination is to mistake the essence of affirmative action. Affirmative action does not in practice promote blindness toward race or sex. As its common name hints, Executive Order 11246 in practice requires contractors to take affirmative action to increase employment opportunities for people chosen on the basis of race and sex, irrespective of whether or not the firm has been discriminating.

In the words of then Under Secretary of Labor, Laurence Silberman: "One of the interesting things about the affirmative action concept, it is not antidiscrimination It goes beyond that... We and the compliance agencies put pressure on contractors to come up with commitments even though these contractors are not guilty of any discrimination, but because we think they are required under the Executive order to go beyond, to provide affirmative action."4 
Speculate a moment on the sources of political support for affrmative action. Why should a politician support affirmative action? Who will support her if she does? Obviously blacks and women are the largest direct beneficiaries of affirmative action, absent civil disorder, and among these one might expect the politician will respond to the wishes of those most likely to support her with votes and money. This suggests a very different conception of how OFCCP regulatory pressure may be targeted.

How does an individual gain from affirmative action? If affrmative action is viewed as a policy of anti-discrimination, she gains from a broader choice set, a feeling of justice and equal protection under the law, and indirectiy from increased earnings. A broader choice of employment only makes the individual better off in effect if she ends up in a better job. Increasing the choice set does not by itself necessarily increase utility. While feelings of justice may promote the authority of the state, they do not put bread on the table. The premise of this section is that political support for affirmative action depends on individual gain in the form of increased earnings.

Relating this in more formal economic terms, political support is proportional to workers' surplus: the area above the supply curve and beneath the wage. Executive Order 11246 imposes employment goals, not wage goals. For a given induced shift in employment, workers surplus will be greater the more inelastic is the supply and will depend not at all on the elasticity of demand. Craphically, for the linear supply in Figure 1 , the increase in worker surplus is $5 \Delta W \Delta N+N_{0} \Delta W$, where $\Delta W$ is the increase in wages, $\Delta N$ is the fixed increase in employment, and $N_{0}$ is initial employment. This surplus increases with $\Delta W$ which increases with the inelasticity of supply $y^{5}$.

If political support is proportional to rents, then the OFCCP will elicit more support from minorities and females by targeting enforcement pressure where supply is inelastic. So affrrnative action pressure should be stronger in occupations requiring high skills and high education, in which people are also more likely to be politically active, and which are after all, in my opinion, the true battlefield of affirmative action. 
It is a battlefield because it is these same cases of inelastic supply that provoke the most political backlash. Firms are more sensitive to quality differentials, have more difficulty meeting employment goals, and are under pressure to raise wages to do so. As their relative wage declines, white males are seized by concern with inequity 6 .

Highly skilled minorities and females have a strong incentive to use the government to increase the demand for their services. This makes an interesting contrast with unions, which sometimes restrict supply, depend for their effectiveness on the elasticity of demand, are more prevalent and at least as important among the lowskilled as among the high-skilled, and which must face a tradeoff between higher wages or more jobs. In terms of redistributing income, the OFCCP acts as an ideal union: it increases wages without decreasing employment for its members; a history of discrimination pays the dues for the group.

\section{Past Study}

Assertions concerning the ends of affrmative action are surprisingly common, especially when one realizes that only once in the past has the actual pattern of enforcement been analyzed. This pathbreaking study by Feckman and Wolpin examined the incidence of compliance reviews at a sample of 1185 Chicago area establishments during 1972. These compliance reviews are the first, the most common, and usually the last step in the enforcement process. Heckman and Wolpin find that the probability of review is not affected by establishment size, minority employment, or change in minority employment. They discover "no evidence of a systematic government policy for reviewing contractor firms". In other words, they find an essentially random enforcement process. This first analysis of targeting studied a relatively small sample in one city during the early 1970's, before the contract compliance program reached full stride. Do these early findings hold true for the nation as a whole after affrmative action regulations and procedures matured? Just as importantly, how are such results to be interpreted? 


\section{Data}

The historical review patterns studied here are based on OFCCP administrative records, made available by the OFCCP's Division of Program Analysis. The records I had access to were not a complete record of all reviews. Rather, these consisted primarily of reviews conducted by the Department of Defense, which accounted for nearly half of all pre-consolidation reviews. For example, while the U.S.C.C.R. reports that 10,647 compliance reviews were conducted in 1976, I have records of about 4300 , of which about half cannot be matched with EEO-1 records because they lack identifying numbers. Conversations with OFCCP officials lead me to believe the remaining underreporting of reviews is largely random.

Separately I assembled a sample of 68690 establishments with matched EEO-1 files in 1974 and 1980 , of which 41281 establishments were contractors in 19747 . I then matched this file with the file of compliance reviews. $6.36 \%$ of the establishments that were contractors in 1974 had completed at least one compliance review in the five years from 1975 to 1979 . Since the reported reviews were primarily conducted by DOD, the sample was then correspondingly limited to those contractors in DOD's territory. According to the U.S. Commission on Civil Rights, DOD had full responsibility for monitoring the compliance of all contractors within the following major industry groups: textile, apparel, printing, publishing, leather, primary metal, fabricated metal, electrical and non-electrical machinery, motor vehicles, aircraft, miscellaneous manufacturing, business services except miscellaneous, rctail automotive dealers, retail apparel stores, and wholesale miscellaneous durable goods, along with a few smaller non-manufacturing sectors not considered here. The results that follow are based on establishments in these industries, which for simplicity will be referred to as defense contractors. This subsample includes 70 percent of all identifiable reported reviews. 


\section{Leaning on Open Doors - Patterns of Enforcement.}

Which establishments does the OFCCP actually choose to review? Can we judge its motives from its targeting policy, and do the goals so revealed conform to those mandated in the Fxecutive Order? The OFCCP has had, on paper, formal targeting systerrs such as the Revised McKersie System or the later EISEN system. These systems generally target in a sensible fashion against discrimination by selecting for review those establishments with a low proportion of minorities or females relative to other establishments in the same area and industry. But interviews with OFCCP officials in Washington and in the field suggest that these formal targeting systems were never really used. Instead of targeting on the basis of an establishment's past demographic record, compliance officers claim they simply reviewed the firms with the most employees, and the growing firms ${ }^{8}$. This section shows which types of establishments were actually reviewed belween 1974 and 1980, primarily by the Department of Defense. As such, the patterns shown here may not be indicative of current policies or practices of the OFCCP, nor of past practices of other compliance agencies.

Before examining actual enforcement patterns, the official OFCCP. policy on compliance reviews may be briefly stated. ${ }^{9}$

"Before OFCCP consolidation, agencies were generally advised to select for review those contractor establishments that offered the greatest opportunities for employment and advancement of minorities and women, taking into consideration such factors as size, location with regard to centers of minority population, turnover rate and EEO profile. Also, regulations required the performance of compliance reviews prior to the awarding of contracts of $\$ 1$ million or more regardless of the relative size of the establishment. Thus, a wide mix of large and small contractors was reviewed. Some agencies endeavored to schedule for review establishments that had relatively poor EEO profiles or were the subjects of numerous complaints from the communi- 
ties in which they were situated. After consolidation, OFCCP directed special efforts to accomplishing reviews in various industries which had not experienced much review activity before, or which were believed likely to contain numerous affected classes of persons of the protected groups."

\section{Bivariate Results}

There are some surprising results in the cross-tabulations presented in Tables 1 to 5, which are not obviously coherent with an efficient targeting strategy. Completely segregated firms-those with either no females or no black males-are among the least likely to be reviewed. Growing establishments are not more likely to be reviewed than stable ones, and the largest establishments are reviewed with less frequency than medium sized ones. Amidst this detail, it is important not to lose sight of the evidence of a comprehensive enforcement effort here. In the years 1975 to 1979 , compliance reviews were reported at 23 percent of all the establishments that were labeled as federal contractors in 1974 in industries for which DOD was responsible before consolidation.

Twenty-two percent of the 7968 contractor establishments reported that they employed no black males in 1974 . Of these, 11 percent were reviewed in the subsequent years 1975 to 1979 . In contrast, 25 percent of the establishments that were twenty percent or more black male were reviewed. Table 1 reveals no consistent pattern of reviews as a function of percent black male. The establishments most likely to be reviewed in Table 1 are those with between ten and twenty percent black male, well above the mean black male representation of six percent. Establishments at either tail of the distribution, with either few or many black males, were less likely to be reviewed. Caution must be exercised in interpreting this finding, since we have not yet corrected for geographic area. In particular, if the establishments with few blacks were all located in areas of the country in which few blacks lived, their low review rates would make more sense. 
Females do not live in ghettos, and can be found even in the farthest reaches of North Dakota, Alaska or Maine. Comparing review frequency by female share, Table 2 demonstrates a less easily explained inconsistency. None of the 74 establishments without any female employees were reviewed. More likely to be reviewed were establishments at the other end of the scale: 28 percent of the establishments that were 70\% or more female were reviewed. The highest incidence of review, 30 percent, occurred among establishments that were 35 to 40 percent female, above the mean female share of 32 percent.

A more sensible pattern of reviews ernerges across establishments of different sizes. The smallest establishments are the least likely to have been reviewed, as Table 3 indicates. Only 5 percent of the quarter of establishments with fewer than 100 employees in 1974 were reviewed in subsequent years. New regulations proposed early in the Reagan administration would have reduced the burden of affirmative action regulation for establishments with less than 250 employees. Table 3 suggests the political turmoil over the issue turned in some part on its symbolic importance, since less than twelve percent of such small contractor establishments had been reviewed. Compliance reviews have always been concentrated at large establishments. The economies of scale in targeting large establishments must be balanced against the benefits of maintaining some perceived pressure on smaller establishments. It is also worth noting that other work suggests that the contractor compliance program has had a greater relative impact on minority and female employment at larger establishments.

The other notable finding in Table 3 is that review incidence peaks at mid-size establishments with 750 to 1000 employees. If economies of scale were dominating the targeting of reviews then one would expect review intensity to increase monotonically with size, but in Table 3 the largest establishments with more than 1000 employees are less likely to be reviewed than mid-size establishments. 
In conversations OFCCP officials have said they also try to target growing establishments that will have grealer opportunities to hire minorities and females without directly displacing white males. This does not appear to be the case in Table 4 . While establishments that experienced a 30 percent or greater reduction in their work force between 1974 and 1980 were slightly less likely to be reviewed than those that grew by 30 percent or more, the differences in review incidence by growth rate are not marked. However, fluctuations at small establishments may be obscuring the underlying patterns within size classes ${ }^{10}$.

The intensity of review does differ greatly across sectors, as Table 5 demonstrates. Fewer than six percent of all contractors were reviewed in the nonmanufacturing sectors for which DOD was responsible. Since large establishment workforces in these sectors are rare, this is probably a function of size. Within the manufacturing sector, the incidence of reviews ranged from 12 percent in printing and 17 percent in fabricated metal, up to 39 percent in apparel and 42 percent in textiles.

\section{Multivariate Results}

Here we expand on the previous findings by controlling for differences across a number of variables at the same time in logit estimates of the probability of undergoing a compliance review. The estimates in Table 6 indicate that the establishments least likely to be reviewed for compliance are those that are $100 \%$ white male, and this is significant. Establishments with less than three percent non-white male are significantly less likely to be reviewed than those with more than fifteen percent. Just. as disturbing, establishments with less than twenty percent female are significantly less likely to be reviewed than those with more than fifty percent. In other words, the greater the proportion female or minority male, the more likely to be reviewed ${ }^{11}$. This is just the upposite of what one would expect from a program targeted against the most simple sort of prima facie discrimination. 
The model of affirmative action as an earnings redistribution program has two testable implications. One can at best offer weak support for the hypothesis, while the secund can provide somewhat stronger support. The first is that no particular pressure should be applied to firms with relatively few minorities or females. This is just what we observe in Table 6. While this strongly rejects the model of affirmative action as anti-discrimination in employment, it offers weak support for the alternative hypothesis of affirmative action as earnings redistribution because it is also compatible with other models of regulatory behavior. The second implication of the earnings redistribution model is that greater pressure should be brought to bear to shift demand curves where the supply of labor is relatively inelastic. In particular, this implies a higher incidence of compliance reviews at establishments with non-clerical white-collar intensive workforces. Again, Table 6 offers strong and significant evidence that this is exactly what the OFCCP has done, supporting the hypothesis that affirmative action is an earnings redistribution program.

Larger establishments are more likely to be reviewed, although this tails off among the very largest. Of course, establishment size is not synonymous with firm size. Some of the sanctions used, such as backpay, are primarily a function of establishment characteristics. Debarment, on the other hand, affects an entire corporation. In light of such explicit or implicit spillovers between the establishment and the corporation, firm size and corporate structure should play an important role. Table 6 indicates that establishments that are part of multi-plant corporations are significantly more likely to be reviewed, as one would expect if economies of scale across the corporation were important.

Note also that growing establishments, which could best accommodate the pressures, are not significantly more likely to be reviewed. By industry, reviews are significantly less likely in printing, but. significantly more likely in textiles, apparel, machinery, and electrical equipment. 
One must question a process that results in multiple reviews at many establishments that employ an above average proportion of minorities or females, while at the same time seventeen percent of the contractors do not seem to realize that they are federal contractors subject to the obligations of affirmative action.

Part of the relatively low probability of review among predominantly white male establishments may be explained by the high within region variance in black population share, especially outside the South, which is not directly controlled for in Table 6 . However, this type of argument is unlikely to accounl for the peculiar pattern among females, who are homogeneously distributed geographically $1 \hat{2}$. We turn next to a test at a finer level of geographic detail.

\section{Compliance Review Targeting in America's Largest Cities.}

The drawback of the last table is that it controls only roughly for local labor market conditions. This is potentially troublesome given the dispersion in minority share within regions. Table 7 refines the multivariate analysis for six of the nation's largest SMSAs: New York, Los Angeles, Chicago, Philadelphia, Detroit and San Francisco.

Even at this fine level of geographic detail in which the idiosyncrasies of local labor markets are controlled for, the targeting of compliance reviews still shows anomalous and perverse patterns.

Most striking, the few establishments with no female employees are significantly less likely to be reviewed than those with at least one female employee. The greater the proportion female, the greater the chances of being reviewed, although the differences across establishments with at least one female employee are insignificant. In particular, the probability of review for an establishment with more than 50 percent

* female does not differ significantly from that for one with from 1 to 50 percent female.

Establishments with no non-white males are not significantly more likely to be reviewed than those with more than 15 percent. Those with six to ten percent 
minority males, still well below the sample mean of seventeen percent, are significantly less likely to be reviewed than those with more than fifteen percent.

Some of the disturbing patterns previously ubserved with rougher geographic controls are reduced here, but not enough to produce a pattern of sensible targeting against discrimination. There is no evidence here that establishments with the smallest proportion of minorities or females, ceteris paribus, are consistently more likely to be reviewed for compliance with Executive Order 1124.6. Again, reviews are significantly more likely to take place, ceteris paribus, in non-clerical white-collar establishments 13 . Taken together with the evident lack of greater pressure on establishments with relatively few minorities or females, this suggests the contribution the earnings redistribution model may make to understanding affirmative action.

\section{Conclusions}

If one thought of the OFCCP's primary concern as fighting discrimination directly in the workplace, one might then expect reviews to be concentrated at establishments with a relatively small proportion of females and black males, controlling for size, industry and region. There is little consistent significant evidence of this is the past. There is significant evidence here that the dominant targeting practice as stated in interviews and as confirmed in Table 6 and 7, is to review large establishments. If political support for the OFCCP were a function of workers' surplus, one would expect to see compliance pressure targeted where labor dernand was inelastic. Tables 6 and 7 show that establishments with proportionately more non-clerical white-collar jobs are significantly more likely to be reviewed.

How can the lack of a consistent targeting pattern by race or sex be explained? The larger establishments often employ a greater proportion of minorities and ferrales. In interviews, field officers of the OFCCP have stated that they do not generally look at an establishment's past demographic record in targeting reviews. Reviewing large non-clerical white-collar intensive establishrnents with little regard for 
their past record of minority or female employment is consistent with an affirmative action effort that is primarily concerned not with attacking the grossest prima facie forms of current employment discrimination, but rather with redistributing jobs and earnings to minorities and women. 


\section{NOTES}

1. A more complex model for richer empirical data might also include the respective dependence and vulnerability to threats of the contractor and the government, spillover effects on labor demand and supply across firms, regions, groups and time, reputation effects, a regulatory production function, and a multi-stage screening and penalty procedure. Some of these variants are explored in other work. (Leonard, 1983).

2. Neither scenario can justify zero review probabilities. Even leaving aside the counterproductive long-run incentives, there is no consistent evidence that segregated establishments are more intransigent. In the subsample of establishments with less than $3 \%$ black male employment, reviews still have a strong and significant effect, and one that is not significantly less than in other establishments. Similarly, the South does not differ significantly from the rest of the nation in its response. On the other hand, in establishments with less than $10 \%$ white female employment-primarily in transportation, utilities and wholesale trade- there is some evidence that reviews reduce white female employment. Both these results are sensitive to specification, but in general it cannot be presumed that little could be gained in the short-run by reviewing white male intensive establishments.

3. We concluded above that confronted with two firms with the same level of below average black representation, the regulator should pursue the larger firm because the evidence in favor of discrimination becomes more statistically compelling with firm size. This conclusion must be tempered by placing the OFCCP within its broader regulatory and legal context. Recourse to the OFCCP is not the sole avenue open to victims of systematic discrimination: they may also bring suit privately or through the FEOC under Title VII. The statistical evidence in large firms that is compelling to the OFCCP is also compelling in the courts. By the 
same token, the OPCCP can pursue less compelling cases which stand less chance of success in the courts. Given its limited resources and comparative advantage, this suggests that the OFCCP temper its pursuit of large firms and divert some resources towards cases that are not likely to be resolved in private litigation because they fall short of court standards.

4. Laurence H. Silberman, Testimony at Hearings of the Senate Subcommittee on Labor of the Committee on Labor and Public Welfare, 92nd Congress, 1 st Session, p.88 (1971).

5. The premise of the above discussion is that no political support would be forthcoming from markets with elastic supply because no workers surplus could be generated. If supply is perfectly elastic at wage $W_{0}$, then workers are indifferent between a given occupation and other pursuits, so they derive no net benefit from employment in the given occupation. This interpretation depends critically on the assumption of perfect labor markets. In reality this assumption is violated by the functioning of labor unions, by government regulations such as minimum wage and occupational licensing laws, and by the presence of involuntary unemployment. In any of these cases an excess notional labor supply may exist, either because wages are artificially maintained above the market clearing level, or employment is constrained below that level by institutional restrictions or by firms' output constraints. If observed wages do not clear markets, an unchanging wage in response to a shifting demand (elastic effective supply) cannot be taken as evidence of elastic notional supply. The argument that political support is strongest where supply is inelastic refers to notional, not effective supply, and goes through even in the presence of wage floors imposed by unions or the government.

6. An interesting question, of course, is who bears the burden of the affrmative action tax. If protected group employment gains can only be obtained by an 
absolute reduction in labor demand for white males, then we must assume that political support is a non-linear function of worker's surplus. This allows large gains for relatively few blacks to outweigh small loses for many white males-concentrated benefits outweigh diffuse costs. On this basis, one expects greater conflict in the case of females, whose greater numbers in many occupations preclude their being so easily accornmodated.

7. $9 \%$ of the study sample are no longer reported as contractors in 1980 . They are unlikely to alter the main results reported here, especially since the mode year of review is rather early: 1975 . The sample is not limited to establishments which were contractors in both 1974 and 1980 because exil. from contractor status may be endogenous to the review process, as it certainly is in the case of debarments.

8. In trying to make sense of how the OFCCP has actually targeted enforcement, it is useful to recognize that the OFCCP, like any other manmade bureaucracy, is imperfect. Fiven if the head knew exactly what it wanted to do, the feet often have their own interests and sometimes are stuck in the mud. An extreme is perhaps the compliance officer who, tiring of a persistent questioners obtuse refusal to accept 'ad hoc' as a complete description of targeting strategy, finally explained as one might to a child, that he had a summer place by the beach and so reviewed oceanside establishments during the summer. In practice, targeting at the OFCCP has for the most part been done on an ad hoc decentralized basis, with field officers exercising considerable discretion. Field officers tend to be evaluated on fulfilling goals for compliance reviews, rather than on successfully bringing discriminators to heel. Indeed to do otherwise might well invite undesirable headhunting. The fastest way to fill a production goal for compliance reviews is to review firms with good records and good behavior. In practice these will usually be large firms with well-established systematic record keeping for internal personnel bureaucracies. They will also tend to be the good corporate citizens 
who have been reviewed before and found in compliance. If this were in fact the internal incentive system for field officers, it would not be surprising, from a bureaucratic perspective, to find that compliance reviews are concentrated on the largest firms that bave already been reviewed in the past, and that already employ the most females and minorities.

9. Letter frum J. Griffn Crump, Special Assistant to the Director, OFCCP, December 21,1982 .

10. In regressions of employment growth on reviews and other variables, including controls for initial size, there is significant evidence of higher growth rates among reviewed establishments.

11. One might speculate that establishments reviewed after 1974 are those not reviewed earlier, and so are not the worst offenders. This is doubtful first because 1974 is still an early year in the history of affirmative action, especially for women; second because Heckman and Wolpin find no evidence of such a policy in 1972; third because unless the OFCCP and its predecessors suddenly abandoned a worst-first policy after 1974, evidence of such a policy should be apparent here; and fourth because multiple reviews are not rare. Again, if such multiple reviews were based on lack of progress from a poor initial position, I would expect to find evidence here that reviewed plants were relatively minority and female poor. Note also that Heckman and Wolpin report that the probability of a review was not affected by the change in minority employment.

12. The all white male establishments are geographically dispersed, but two-thirds of them are in the primary and fabricated metals industries, with concentrations in the 3-digit SIC industries miscellaneous primary metal products, metal cans and shipping containers, and fabricated structural metal products. Non-clerical white-collar workers make up less than $10 \%$ of the workforce in these plants. Segregated plants may be in specialties in which the supply of qualified minorities 
or women may be low (though not clearly more so here than elsewhere) but this is not an argument the OFCCP bows to readily, and certajnly not before a review.

13. I do not mean to claim here that the targeting of reviews is fully explained by the earnings redistribution model, only that the implications of the anti-

discrimination model are not to be found in the data, and that the earnings redistribution model does help explain the lack of systematic pressure on establishments with low protected group employment together with evidence of greater pressure on white-collar intensive employers. Given some evidence that reviews are perverse, not just random, with respect to protected group cmployment share, the full rationality of the review process should not be asserted on the basis of the estimated relationship between reviews and white-collar intensity. In this regard it is worth noting that even when the six-city analysis is replicated for the subsample with above average white-collar intensity, the anomalous targeting with respect to protected group employment share found in Table 7 persists. 


\section{References}

Ifeckman, James and Kenneth Wolpin, "Does the Contract Compliance Program Work? An Analysis of Chicago Data" Industrial and Labor Relations Review, 29(July 1976):514-564.

Ieonard, Jonathan S., "The Impact of Affirmative Action". U.S. Department of laabor report, July, 1983. 
Figure 1

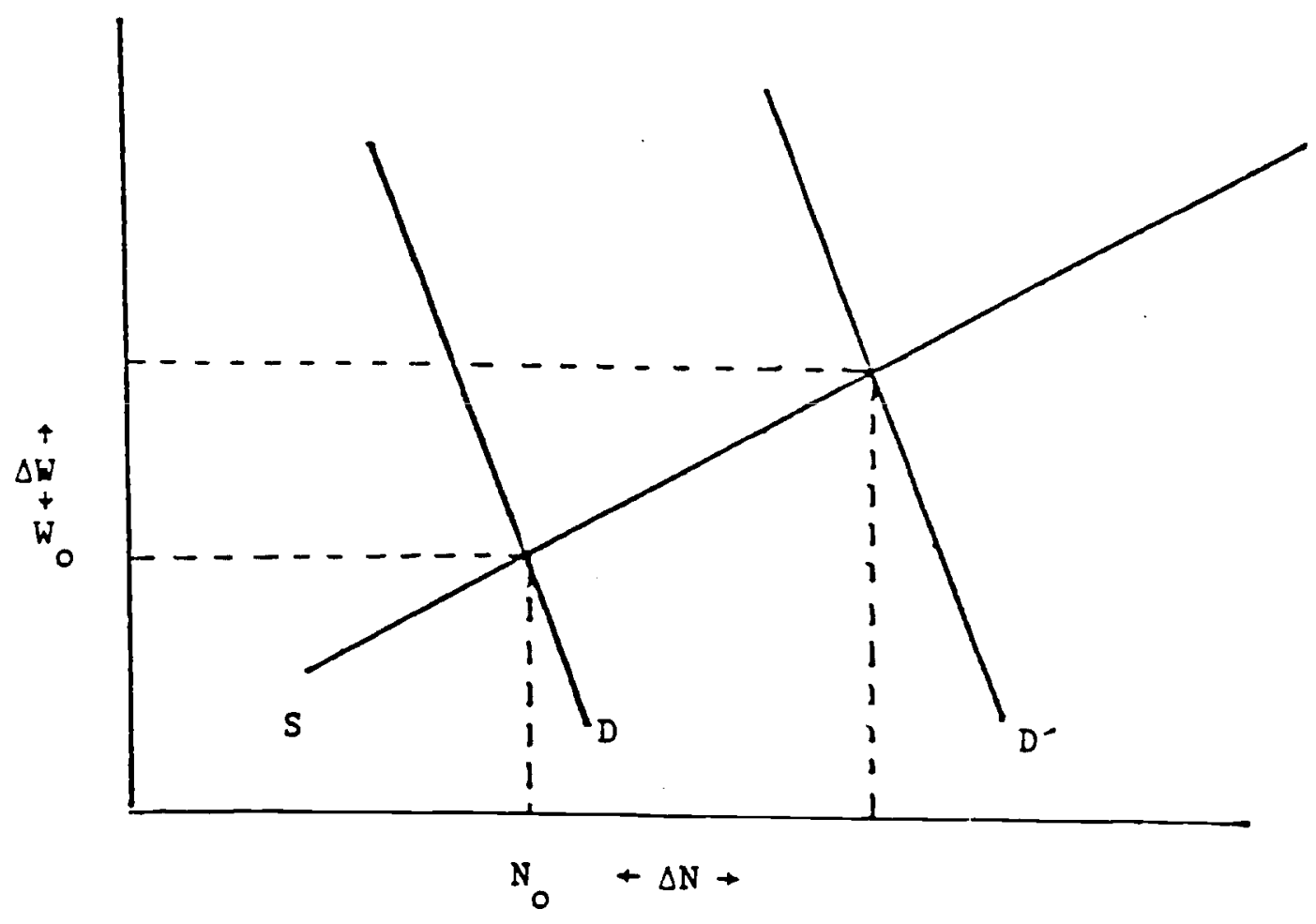


Table 1: Proportion of Defense Contractor Establishments That Were Reviewed from 1975 to 1979, by 1974 Black Male Employment Share.

$\mathrm{N}=7968$ Establishments

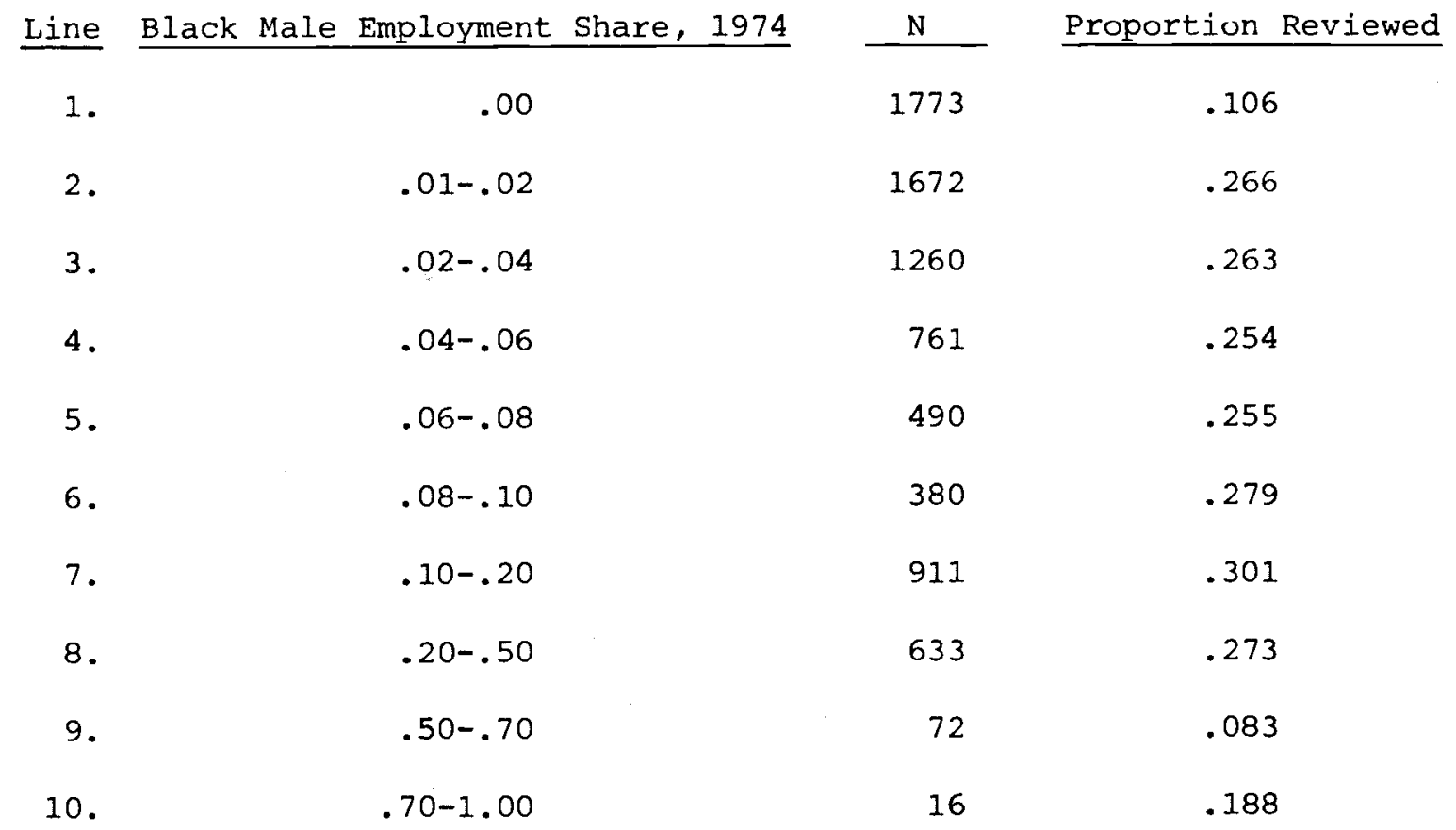


Table 2: Proportion of Defense Contractor Establishments That Were Reviewed from 1975 to 1979, by 1974 Female Employment Share.

$\mathrm{N}=7968$ Establishments

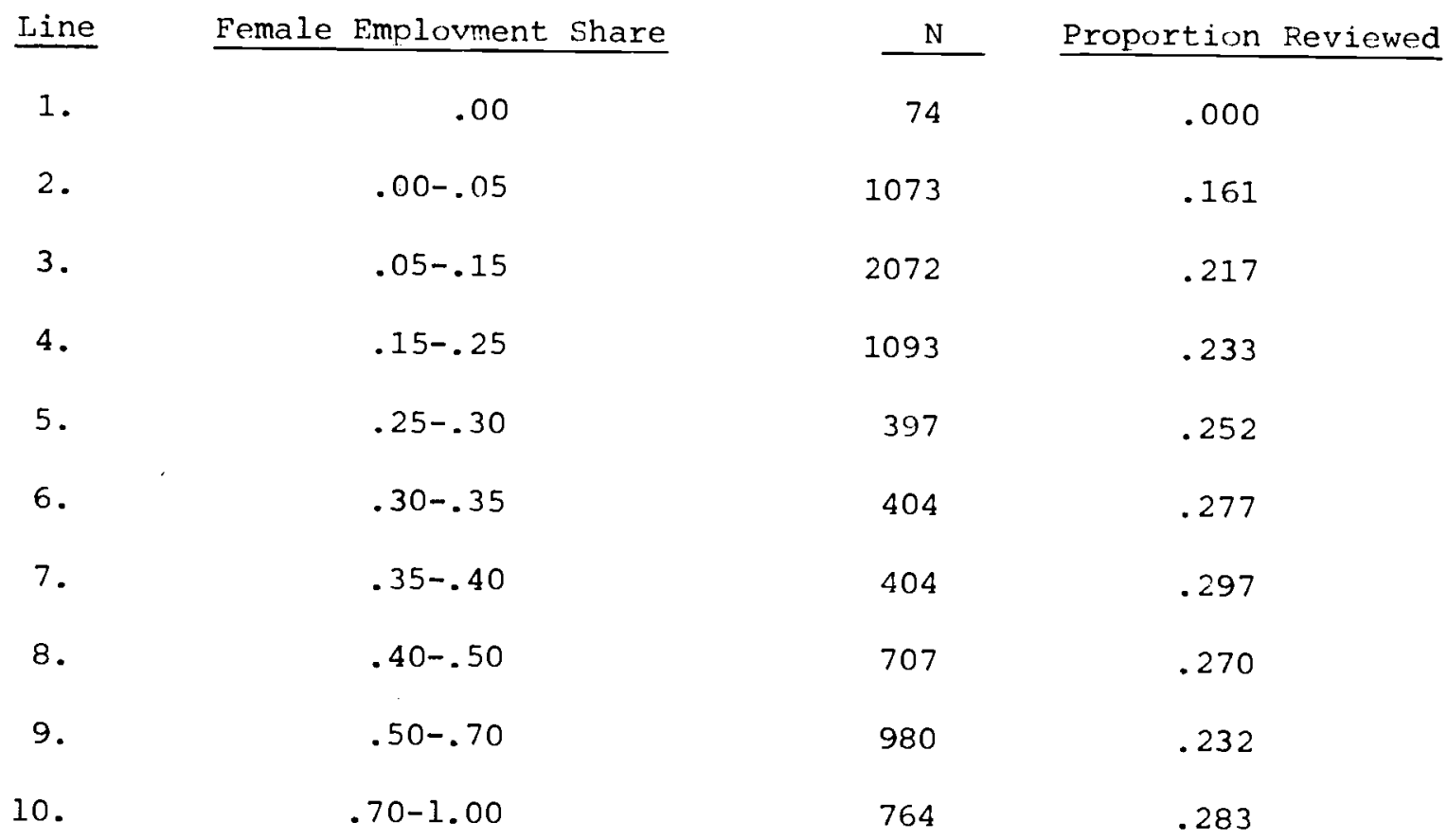


Table 3: Proportion of Defense Contractor Establishments That Were Reviewed from 1975 to 1979, by 1974 Total Number of Employees.

$\mathrm{N}=7968$ Establishments

\begin{tabular}{|c|c|c|c|}
\hline Line & Size & $\mathrm{N}$ & Proportion \\
\hline 1. & $1-50$ & 702 & .030 \\
\hline 2. & $50-100$ & 1244 & .060 \\
\hline 3. & $100-250$ & 2489 & .172 \\
\hline 4. & $250-500$ & 1611 & .326 \\
\hline 5. & $500=750$ & 697 & .405 \\
\hline 6. & $750-1000$ & 372 & .450 \\
\hline 7 . & $1000-2000$ & 450 & .440 \\
\hline 8. & $2000-5000$ & 278 & .380 \\
\hline 9. & $5000-8000$ & 78 & .290 \\
\hline 10. & $8000+$ & 47 & .310 \\
\hline
\end{tabular}


Table 4: Proportion of Defense Contractor Establishments That Were Reviewed from 1975 to 1979, by Growth Rate of Total Employment from 1974 to 1980.

$\mathrm{N}=7968$ Establishments

$\begin{array}{lcccc}\text { Line } & \text { Growth Rate } & \mathrm{N} & \text { Proportion Reviewed } \\ & \text { less than }-.30 & 1247 & .205 \\ 2 . & -.30 \text { to }-.10 & 1660 & .231 \\ 3 . & -.10 \text { to } .10 & 1927 & .246 \\ 4 . & .10 \text { to } .30 & 1277 & .233 \\ 5 . & \text { greater than or equal to } .30 & 1857 & .233\end{array}$


Table 5: Proportion of Defense Contractor Establishments That Were Reviewed from 1975 to 1979 by Industry. $\mathrm{N}=7968$ Establishments

\begin{tabular}{|c|c|c|c|c|}
\hline Line & Sector & SIC & $\mathrm{N}$ & $\begin{array}{l}\begin{array}{l}\text { roportio } \\
\text { Reviewed }\end{array} \\
\end{array}$ \\
\hline 1. & Textiles & 22 & 597 & .424 \\
\hline 2. & Apparel & 23 & 364 & .393 \\
\hline 3 . & Printing & 27 & 478 & .115 \\
\hline 4. & Leather & 31 & 137 & .117 \\
\hline 5. & Primary Metal & 33 & 805 & .190 \\
\hline 6. & Fabricated Metal & 34 & 1327 & .171 \\
\hline 7. & Machinery & 35 & 1491 & .231 \\
\hline 8. & Electrical Equipment & 36 & 1279 & .322 \\
\hline 9. & Transport. Equip., Air \& Land & $371-372$ & 687 & .249 \\
\hline 10 . & Miscellaneous Manufacturing & 39 & 211 & .190 \\
\hline 11. & Wholesale Misc. Dur. Goods & 509 & 115 & .052 \\
\hline 12. & Retail Car Dealers & 551 & 7 & - \\
\hline 13. & Retail Apparel Stores & 56 & 67 & .015 \\
\hline 14. & Business Services & $731-738$ & 403 & .057 \\
\hline
\end{tabular}




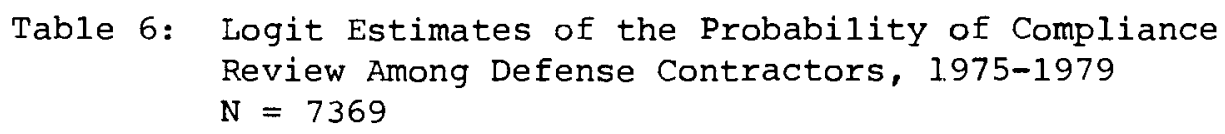

Variable

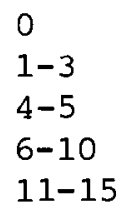

North-East

Plains

South

west

Size

Size $^{2}$

Growth

\& Non-clerical white-collar

Single

Textiles

Apparel

Printing

Leather

Primary metal

Fabricated metal

Machinery

Electrical equipment

Transport equipment

Intercept

MSE

Mean proportion reviewed

Asymptotic

Estimate

$$
-.93
$$

$-.25$

$-.037$

$-.037$

.064

$-3.49$

$-.53$

$-.28$

.05

$-.03$

$-1.31$

$-.35$

.14

$-.34$

$-5.000670^{-8}$

.0074

.59

$-1.12$

.53

.90

$-.55$

$-.46$

.31

.17

.51

.67

.31

$-.99$

.156

.246
Standard Error

Mean

.094

.131

.236

.121

.182

.098

.081

.096

.009

.277

.090

.096

.309

.180

.091

.086

.203

.10

.44

.14

.07

.30

.13

.11

585

$4.000040^{-9}$

.013

2233608

.21

.20

.11

.08

.08

.05

.06

.02

.11

.18

.20

.17

.09

.16

.17

.19 
Table 7: Logit Estimates of the Probability of Compliance Review Among Defense Contractors in the Nation's Six Largest Cities, $1975-1979$

$\mathrm{N}=1304$

\section{Variable}

$$
0
$$

s Non-white Male

$1-3$

4-5

6-10

11-15

o F Female

$1-10$

$11-20$

21-28

29-50

Los Angeles

Chicago

Philadelphia

Detroit

San Francisco

Size

Size 2

Growth

\& Non-clerical white-collar

Single

Textiles

Appare1

Printing

Leather

Primary metal

Fabricated meta 1

Machinery

Electrical equipment

Transportation equipment

Intercept

MSE

Mean Proportion Reviewed
Asymptotic

Estimate

Standard Error

Mean

$$
\begin{array}{r}
.027 \\
-.73 \\
-.24 \\
-.53 \\
.30
\end{array}
$$

$-3.00$

$-.44$

$-.30$

$-.33$

$-.32$

$-.47$

$-2.57$

$-.53$

$-8.41$

$-1.38$

$-2.0022-7$

.072

1. 22

-. 1.49

.46

$-.27$

$-.80$

$-4.15$

.72

.57

.72

1.00

.60

$-1.52$

.28

.25

.26

.19

.21

.71

.24

.24

.27

.22

.23

.23

.27

.28

.30

.065

.113

.094

.184

.133

.008

.299

.210

.110

.224

.257

.273

.133

.158

.073

.00009

613

2700704

.028

.202

.261

.114

.20

.013

.024

.097

.006

.098

.219

.221

.174

.122

\section{.107}

.179 